\title{
ВИРТУАЛЬНАЯ САМОПРЕЗЕНТАЦИЯ \\ В КОНТЕКСТЕ ИДЕНТИЧНОСТИ
}

\author{
Багаева Элиса Петровна \\ аспирантка \\ Научный руководитель: Марков Александр Петрович \\ профессор, доктор культурологии, доктор пед. наук \\ НОУ ВПО «Санкт-Петербургский Гуманитарный \\ Университет Профсоюзов»
}

\begin{abstract}
Аннотация: В статье рассматриваются особенности виртуальной самопрезентации в контексте идентичности. Автор дает рефлексию на концепты ряда исследователей по трактовке виртуальной самопрезентации и идентичности личности. Эгоистическое стремление человека транслировать в виртуальном пространстве свое «Я» в формате лучшей версии столкнулось с рядом проблем морально-нравственного, ценностно-нормативного плана, что влияет на его гармоничное существование в реальном мире. Предложено проанализировать культурологические основания идентичности в контексте социально-виртуальной деятельности индивида, технологии самопрезентации, способных оказывать существенное воздействие на сознание и поведение личности.
\end{abstract}

Ключевые слова: Виртуальное пространство, виртуальная личность, самопрезентация, идентичность, социальные сети, Интернет-коммуникации.

\section{VIRTUAL SELF-PRESENTATION IN CONTEXT OF PERSONAL IDENTITY}

\section{Bagayeva Elissa Petrovna Markov Alexander Petrovich}

\begin{abstract}
The article discusses the features of virtual self-presentation in the context of identity. The author gives a reflection on the concepts of a number of researchers on the interpretation of virtual self-presentation and personal identity. The egoistic desire of a person to broadcast his "I" in the virtual space in the format of the best version has encountered a number of problems of the moral, value-normative
\end{abstract}




\section{ИННОВАЦИОННЫЙ ДИСКУРС РАЗВИТИЯ СОВРЕМЕННОЙ НАУКИ}

plan, which affects his harmonious existence in the real world. It is proposed to analyze the cultural foundations of identity in the context of social and virtual activity of the individual, the technology of self-presentation, which can have a significant impact on the consciousness and behavior of the individual.

Key words: Virtual space, virtual personality, self-presentation, identity, social networks, internet communications.

Введение. Современное общество, характеризующееся растущей цифровизацией во всех сферах проявления человеческих потребностей и интересов, столкнулось с эгоистическим стремлением человека как индивида определенного сообщества транслировать себя как особого неповторимого «Я» в виртуальном информационном пространстве этого сообщества. Такая рефлексия рассматривается как одна из попыток идентификации субъекта через виртуальную самопрезентацию.

Несмотря на наличие немалого количества исследований различных представлений о виртуальной самопрезентации, мы можем отметить, что работ интегрированного культурологического характера, в которых данный феномен рассматривается в широком социо-культурном контексте, в качестве агента социальной политики, своеобразного института социализации, недостаточно. Вне научно-познавательного поля остаются культурно-антропологические основания идентичности в контексте социально-виртуальной деятельности индивида, анализ технологий самопрезентации, способных оказывать существенное воздействие на сознание и поведение представителя нового общества, что придает данному исследованию особую актуальность.

Наш гипотетический постулат сводится к стремлению индивида создавать и поддерживать образ идеального «Я», что влияет на его гармоничное существование в реальном мире. В парадигме виртуального мира результатом подобных действий внутри сети становится создание феноменаалгоритма, который несмотря на свою ирреальность, наполняется жизнью, характером, энергией и способен растворить в себе все жизненные чаяния реальной личности, разрушая ее внутренний мир, формируя инфантильную рефлексию на происходящее, рост апатии и депрессивных состояний. Это только один из возможных сценариев идентификации личности.

В данной статье мы транслируем представления об идентичности в контексте ее детерминированности процессами, происходящими не только в 


\section{ИННОВАЦИОННЫЙ ДИСКУРС РАЗВИТИЯ СОВРЕМЕННОЙ НАУКИ}

экономико-политической или социально-культурной сфере. Практика сегодняшнего дня свидетельствует, что с изменением технологий, созданием инновационных механизмов производства, передачи и распространения информации, с необходимостью трансформируются ментальность и мировоззрение личности. Такие общемировые процессы как глобальная экономическая интеграция, финансовые и политические кризисы, информационная, сексуальная революции - все это преобразовывает даже самые консервативные социальные институты, не говоря уже о личностном мироощущении, мировосприятии и восприятии обществом отдельного индивида. За счет активизации миграционных процессов происходит интенсификация межэтнических отношений и контактов, виртуальные субъекты - сети делают возможным процесс перманентной межличностной коммуникации, как следствие, трансформируются и смещаются критерии, определяющие этничность, национальность, подвергаются пересмотру критерии гражданства, родства и даже вопросы гендерной принадлежности. В итоге эта многообразная и фрагментированная реальность актуализирует интерес к человеку.

Материалы и методы. Поиск идентичности стимулирует познание человеком своей сущности, вселенского предназначения под углом сущностных ориентиров и доминант целеполагания. Неоднозначные процессы стирания временно - пространственных граней, «идолов» традиционных норм и правил и техническое оснащение позволяет ранее невозможное - рефлексии, проявляющиеся мгновенно в постах, блогах, видео и аудио формах-фактах, становящихся достоянием мировой глобальной сети. В таких условиях трудно не потерять себя, свое «Я».

В эпоху информационных преобразований трансформируется формат социальных интеракций (коммуникаций). Они все чаще предстают косвенными, а не прямыми, как раньше, и, как следствие, это влечет изменения в процессах идентификации человека. И, как конкретный результат глобальной технологической революции - отчуждение, дефицит межчеловеческих (межличностных) связей, их стабильности и определенности. С возрастанием значения информации, как основного атрибута эпохи, средств ее передачи, а главное ее количество затрудняют понимание не только окружающего мира, но и формируют множество иных сложностей для человеческой психики. Именно в этой связи вопрос об идентичности в контексте социальных изменений, 


\section{ИННОВАЦИОННЫЙ ДИСКУРС РАЗВИТИЯ СОВРЕМЕННОЙ НАУКИ}

вызванных информационной революцией и, в частности, появлением новых средств информирования и коммуникации, представляется крайне актуальным.

Идентификация в условиях роста влияния информационных технологий и средств массовой информации становится центральной и повседневной проблемой для каждого.

Под идентичностью подразумевают результат процесса идентификации человека, то есть его отождествление либо с самим собой, в обусловленности и перманентности собственной изменчивости, либо с чем-то иным, например, будь это определенная личность или целая общность.

В научной среде сложилось три дисциплинарно различных понимания идентичности: первое - в логике (неклассической), второе - в философии (прежде всего неклассической, и, главным образом постклассической), третье в социогуманитарном (социология, антропология, психология) знании (отчетливо артикулированное в 1920-1930-е годы, а с конца 1960-х - одно из центральных понятий большинства культуроориентированных дискурсов). С 1980-х явно обозначилась тенденция к универсализации понятия идентичность и преодолению междисциплинарных перегородок в постструктуралистскопостмодернистской перспективе [1, с. 445 - 447].

Трактовка идентичности объединяет несколько аспектов. Цель современной парадигмы науки - совместить в понимании различные аспекты жизнедеятельности. Философия исследует вопросы человеческой целостности, определяя фундаментальные основы бытия человека в мире (онтология). В социологии идентичность рассматривается с точки зрения общества и его институтов (комплекс ролей и статусов). В психологии акцент делается на рефлексии внутренних процессов (психические свойства и состояния).

C нашей точки зрения, в противовес философским теориям, претендующих на раскрытие сущности «Я», психология дифференцирует проблему на составные части, под углом экспериментальных исследований: по предмету, по теоретическому контексту, по компонентам образа «Я». Общеизвестно, адекватный подход с необходимостью должен сочетать (синергия) обе части - внутреннюю самореализацию и внешний контекст. Корреляция принципов общей методологии приводит к необходимости комплексного, междисциплинарного подхода.

В данном контексте вызывает интерес точка зрения Заковоротной М. В., которая считает, что для полного многостороннего изучения феномена 


\section{ИННОВАЦИОННЫЙ ДИСКУРС РАЗВИТИЯ СОВРЕМЕННОЙ НАУКИ}

идентичности необходимо ориентироваться на результаты следующих научных дисциплин:

- физическая антропология - выявляет соотношения биологического и социального, стереотипов мужского и женского, условий питания и хронологии жизни, способов ухода за телом и детьми, норм физического состояния, демографических и физических параметров больших общностей;

- социология - анализирует процессы социализации, методы и нормы приобщения к обществу, процессы социальной дифференциации и интеграции, автономизации и структурирования, характера принадлежности к группам;

- культурология - исследует содержание духовного мира, особенности культурных традиций, норм, способы идеологического производства, особенности языковых систем, особенности жизни, мифологии и народной культуры, процессы инкультурации и аккультурации человека;

- социальная психология - рассматривает особенности временного, зрительного, слухового восприятия, развития речи, темпы освоения мира, закономерности функционирования индивидуального и коллективного сознания, закономерности развития ценностных ориентации, чувства стыда, страха, потребности в самостоятельности и коллективизме, методы обучения, особенности менталитета,

- экономические науки - исследуют становление экономической системы, особенности рынка, способы движения денег и капиталов, пути организации производства, распределения и потребления, способы контроля, особенности технических и технологических систем,

- синергетика объединяет изучение развития больших систем, информатизации и процессов идентификации,

- информатика - рассматривает информацию как специфический атрибут жизнедеятельности, взаимосвязь информации и идентичности, информации и системы [2].

Следует отметить, что тему идентичности активно использовали в своих исследованиях представители классической, неклассической и неоклассической философии. Они изучали процесс отождествления человека с самим собой и динамику положения отдельного человека в обществе. Здесь не выражен культурологический аспект исследования. В виду этого наш концепт является попыткой рассмотреть идентичность, самопрезентацию, виртуальную самопрезентацию именно через призму культурологического подхода. 


\section{ИННОВАЦИОННЫЙ ДИСКУРС РАЗВИТИЯ СОВРЕМЕННОЙ НАУКИ}

Специфика данного подхода в трансформации рефлексии личностью своего «Я» под углом освоения культурных форм проявления свойств, качеств и характерных черт индивида в новом поле деятельности - социальные сети, виртуальное информационное пространство.

Генезис проблемы идентичности не только многогранен, но и многосложен, и во временном континууме достаточно долог. Зарождение происходит в Новое время, когда человек исторически становится субъектом свободного выбора и несет ответственность за свои деяния (демиург). Саморефлексия и самосознание были атрибутами человека гораздо раньше, как и потребность адекватно применять жизненный опыт в практике повседневности, обыденности.

Философское обоснование термина «идентичность» непосредственно связано с социально-культурной ситуацией в разных исторических периодах. Одними из первых его начали анализировать Д. Локк и Д. Юм. Однако возникновение интереса к феномену индивидуальности отнюдь не означало, что он автоматически завоевал место в истории и теории. Смещение внимания индивида с социальной группы, находящейся в непосредственном контакте в разных сферах деятельности, включая и сферу мышления, на себя, центрированности на своей личности происходило на протяжении долгого времени. Такое положение с неизбежностью указывало на актуальность проблемы самоидентификации, выбора идентичности.

По мере трансформации экономической, социальной, культурной систем и общей архитектонике человеческих взглядов, сама по себе личностная идентичность начинает проявляться еще в эпоху Возрождения.

Процесс самоутверждения личности в формате единичного «Я» протекал в парадигме столкновения разнополюсного поведенческого амплуа - разгул страстей, своеволия и распущенности, религиозный фанатизм, аскетизм и др. Другими словами, индивиды, обладавшие всем для нормальной жизни, нуждались в самоутверждении, выходящем за рамки рутинного течения сытой жизни. Безусловно, такое положение вещей перекликается с современным, когда, удовлетворив, потребности первой необходимости (пища, жилье, продолжение рода), личность также требует заполнения экзистенциального вакуума. Наблюдаются прямые параллели и в изменении ментальности с современным обществом - и сегодня человек стоит перед выбором собственной идентичности. Аналогичный кризис нарративов и крах идеалов 


\section{ИННОВАЦИОННЫЙ ДИСКУРС РАЗВИТИЯ СОВРЕМЕННОЙ НАУКИ}

произошел в конце XX века. Кроме того, перед каждым, так же, как и сейчас, вставала проблема принятия новых моральных норм взамен традиционных, которые на протяжении почти семи десятилетий устанавливала властвовавшая в тот период времени командно-административная система. Парадокс был в нежизнеспособности общепринятой морали («один за всех и все за одного»), которой формально придерживалось большинство, хотя другая часть общества (верхушка, партийная элита и проч.) уже давно существовала по меркам иной индивидуалистической морали.

В общественной системе Нового времени появляется иной человек «действующий», определяющий свои личностно-субъективные границы, имеющие отношение как к пространству, так и времени. Многофакторность, полярность социальной жизни обуславливает потребность и необходимость поиска универсальных форм и критериев поддержки для «Я». В эту эпоху человек стремится найти точку опоры уже не столько в космосе или в Боге. $O H$ вырос в себе самом, в своей углубившейся и расширившейся душе и в своем открывшемся в новом свете теле, через которое ему видится новая телесность вообще. Абсолютизация личности стала для него вселенской точкой опоры.

Историческая справка. В обществе закладываются цуенностно-правовые основания качественно новой культуры - культуры Нового времени. Конкретно по этому поводу говорит М. Хайдеггер: «Природа, начиная с этого времени, становится огромной бензоколонкой, источником энергии для технического оснащуения» [3, с. 1-53]. Кроме того, это время великих географических открытий (Африки и Америки). В странах происходили радикальные политические и сочиально-экономические перемень: рост мануфактур, заводов, фабрик, наемного труда, возникновение движений, отстаиваюших свободу самоопределения (например, политические, студенческие, феминистские, национально- освободительные движения). Большую роль сыграла Франиузская револючия, создав новые дополнительные системь идентификацуии, позволяющче сохранить экзистенцииальную безопасность. Внимание к окружающему оборачивалось интересом к самому себе. И как итог, растет сочиальная значимость «частного» человека. Стремление к интимности привело к тому, что обычным делом становится вести дневники, личные записи, писать письма, биографии, проявлять себя в любовной лирике, иутливых новеллах. 


\section{ИННОВАЦИОННЫЙ ДИСКУРС РАЗВИТИЯ СОВРЕМЕННОЙ НАУКИ}

В современном многофакторном обществе личность с необходимостью обретает самость в константном процессе интерсубъективного взаимодействия, стоит перед необходимостью соответствовать нормам и правилам, детерминируемыми социальными институтами и общественными интересами. В интересах достижения адекватного образа «меня» редуцируется значимость индивидуального «Я». Современный человек всеми способами рефлексивного поведения вынужден постулировать свою самость, прячась за маской, состоящей из символов, статусов и ролей.

Виртуальная самопрезентация в контексте идентичности обусловлена множеством факторов, как объективного, так и субъективного порядка. Как отмечает Мышкина М.С., границами пола, возраста, национальности, профессиональной принадлежности, границами собственного тела [4]. Виртуальная коммуникация скрывает индивида, его невидимость выступает своеобразным щитом от внешних форм проявления и скрывает те его характеристики, которые нежелательны для него в контексте идентичности, т.е. одним из мотивов трансляции в виртуальной коммуникации выступает возможность «убежать из собственного тела» [5, с. 567 - 584].

Литературный обзор. В начале 90-х годов самопрезентация стала объектом активного внимания российских исследователей (Н.В. Амяга, Е.В. Михайлова, О.В. Кошкина и др.), которые этот феномен рассматривали в виртуальном пространстве. Авторы трактовали виртуальное пространство через призму комплексности, многоаспектности как в содержательном, так и количественном измерении - характеристиками выступали уровень личностной зрелости, личностного самоопределения, личностной идентичности [5, с. 213].

В нашем представлении самопрезентация как своеобразное проявление идентичности есть форма социализации, рефлексирующей собой сферы реального и виртуального общения, делая акцент на информационной социализации.

Исследование виртуальной самопрезентации как идентичности обусловлено, прежде всего, психологической составляющей как сущностной характеристики личности, а именно, она как осознаваемое и создаваемое в виртуальной реальности представление человека о самом себе через призму конкретных, условных параметров, выбираемых самим человеком. По мнению. Шкуратова И.П., самопрезентация представляет собой своего рода «игру с идентичностью, давая возможность создать совершенно новый образ «Я», 


\section{ИННОВАЦИОННЫЙ ДИСКУРС РАЗВИТИЯ СОВРЕМЕННОЙ НАУКИ}

одним из определяющих условий чего выступает анонимность общения в сети Интернет. [6, с.45].

Культурологический аспект данного феномена предполагает многообразие возможностей рефлексии индивида, в частности, он может создать свой индивидуальный стиль коммуникации в виртуальном пространстве - от псевдонима до детализации поведенческих, мировоззренческих, деятельностно-культурных и др. видов собственной активности в социуме. По мнению Сураевой Г.3., несмотря на всю условность виртуального существования, его базовым мотивом является репрезентация личностью своих подлинных свойств, направленная на ее самоутверждение, минимизация сомнений в подлинности сомнений [7]. Данный угол зрения дает возможность анализа мотивов и смыслов интенции личности, представляющую собой системное образование, которое определяет область «значимого» личности. Следует учитывать, что актуальные мотивы реализуются в конкретных ситуациях настоящего личности, а мотивационно-смысловая интенция нацелена на будущее - в контексте предвосхищения и подготовке будущих ситуаций [8]. Виртуальное пространство обеспечивает такой спектр возможностей для личной самопрезентации, что вопрос только в том - каковы содержательные особенности мотивационно-смысловой интенции личностной самопрезентации.

Полем виртуальной самопрезентации становятся социальные сети, такие как «Вконтакте», «Facebook», «Instagram», «Tik-tok», «Одноклассники» и др. Они агрегируют на своих пространствах интересы самых разноликих аудиторий, как по возрастному, этническому, статусным позициям, так и по генедерному составу, образовательному уровню и др. Социальные сети замещают собой практически все традиционные форматы общения:они выступают не только местом виртуальной коммуникации, но и «стилем жизни» многих пользователей названных сетей. Это объясняется тем, что социальная сеть есть способ поиска и нахождения новых знакомств, друзей, слушателей, единомыщленников. И как справедливо отмечают Антонова Н.В. и Одинцова М.С., именно поэтому стоит говорить о значимости самопрезентации в интернет пространстве. Таким образом, основная функция страницы пользователя в социальной сети - рекламаная: обратить внимание других пользователей на себя, инициировать общение [9, с. 5 - 16]. 


\section{ИННОВАЦИОННЫЙ ДИСКУРС РАЗВИТИЯ СОВРЕМЕННОЙ НАУКИ}

По мнению О.А. Гримова, возникли разные каналы для самопрезентации в виртуальном поле-пространстве, например, такие - никнейм (прозвище пользователя в «онлайновой жизни»); аватар (картинка или фотография, своеобразное визуальное изображение образа пользователя); статус (индикатор текущего состояния) и др. [10, с. 34 - 39]. Наряду с перечисленными каналами, выделяют еще и размещение результатов своей работы - продуктов собственного творчества; фото и видеоматериалы, которые посвящены пользователю или имеют к нему отношение. Особое внимание и место в структуре виртуальной самопрезентации отводится разделам, в которых содержится информация о личном, об интересах, убеждениях, предпочтениях, отражающих статусные, демографические, образовательные, возрастные и иные характеристики пользователя. На наш взгляд, такая самопрезентация выступает одной из форм самовыражения, рефлексией своего Я, чаще всего в улучшенной версии себя.

Виртуальное пространство представляет собой не только среду, которая предоставляет пользователям как возможность коммуникации, так и ресурсы для самоидентификации и самопрезентации, но и рассматривается как один из важнейших векторов самоконструирования личности в виртуальном пространстве..

Обсуждение. Ранее было отмечено, что самопрезентация трактуется исследователями как «сознательная управляемая передача собеседнику определенной информации о себе [11, с. 37 - 74] или как «поведенческое выражение эмоциональных и когнитивных элементов Я - концепции» [12]. Следует отметить, что передача определенной информации о себе в рамках коммуникативных практик самопрезентации может быть не только полностью сознательным актом, но и частично бессознательным, когда личность наделяет себя желаемыми чертами. В этой связи наше мнение совпадает с точкой зрения В.А. Янчука, в частности, он определяет самопрезентацию как процесс «осознаваемого или неосознаваемого, целенаправленного или стихийного предъявления определенных аспектов своего «Я» окружающим» [13]. Такое понимание дает возможность творческой, креативной рефлексии самопрезентации, что «обеспечивает не только широкое разнообразие ее проявлений, но и потенциальное построение совершенно нового образа, не свойственного пользователю в реальной жизни, служащего для него средством самоидентификации. Подобная игра идентичностями, составляющая согласно 


\section{ИННОВАЦИОННЫЙ ДИСКУРС РАЗВИТИЯ СОВРЕМЕННОЙ НАУКИ}

теории постмодерна сущность идентификации личности, актуализирует противопоставление реального «Я» (или Я - образа), характеризующего пользователя в реальной жизни, и виртуального «Я», т.е. репрезентации образа, воплощенного в виртуальном пространстве Интернет - коммуникации, независимо от реальности наделяющих его характеристик» [13. с. 60].

Размещая информацию, пользователь заинтересован в максимальной успешной интеграции в виртуальный социум через планомерное управление впечатлением о себе на другого. Соколов М.М. считает, что популярность Интернет-коммуникации детерминирована, в первую очередь, желанием создания наиболее положительного Я - образа, в котором нивелируются негативные атрибутивные признаки и выходят на первый план достоинства коммуниканта [14, с. 9 - 39]. По его мнению, в виртуальном пространстве преодолеваются 5 коммуникативных фильтров:

1. культурные - дефицит моделей выражения определенных идей и чувств, предлагаемых наличной культурой;

2. когнитивные - связаны с ограниченными интеллектуальными ресурсами индивида;

3. моральные - обусловлены с норматинными ограничениями на передачу опреленной информации определенной аудитории;

4. стратегические ограничения, которые возникают, поскольку большинство актов передачи информации о себе помещены в контекст других таких же актов, и все участники взаимодействия вступают в него, подозревая, что другие будут вести с ними игру, с целью предпочтительного представления себя;

5. технические ограничения, заключающихся в сложностях доставки нужной информации всем желаемым получателям из-за отсутствия физических возможностей достижения цели [14, с. 63].

Анализ подводит нас к выводу о том, что социальная сеть, виртуальное пространство является не средством построения и создания альтернативной идентичности, а условием виртуализации личности, репрезентации ее в пространстве информационно-коммуникативной культуры путем формирования максимально позитивного Я-образа в поле персональной страницы, выступая конкретным элементом экзистенциального расширения личности.

В этой связи особый интерес связан с определением степени реальности заявляемой в виртуальном пространстве идентичности, т.е. создаваемого 


\section{ИННОВАЦИОННЫЙ ДИСКУРС РАЗВИТИЯ СОВРЕМЕННОЙ НАУКИ}

пользователем виртуального Я-образа. В научной литературе выделяют два базовых подхода:

1. основывается на постмодернистском понимании виртуального пространства, определяющего данные репрезентации [15];

2. акцентирует внимание на стремлении личности к подлинности и самоутверждению (М.М. Соколов, И.В. Костерина) [14].

Обосновывая первый подход Е.П. Белинская отмечает, что определенное соответствие базовых особенностей виртуальной реальности этосу разворачивающегося проекта постмодерна может быть раскрыто по конкретным пунктам. Например, автор выделяет такие пункты:

1. анонимность коммуникации в виртуальности;

2. «игра» с ролями и построение множественного «Я»;

3. единственная реальность личности в виртуальности суть реальность самопрезентации;

4. виртуальное пространство предлагает человеку максимум возможностей для любых видов самоконструирования [15].

В рамках первого подхода самопрезентация субъекта в виртуальном пространстве трактуется как процесс создания и смены «масок», имеющих мало общего с реальным пользователем, вариативный множественный процесс, направленный на креативирование альтернативного образа «Я». Сторонники данного подхода считают, что создание виртуальной личности своего рода рефлексия на неудовлетворенность какими-либо аспектами реальной идентичности, как выражение стремления к реализации агрессивных и манипулятивных тенденций и пр., своего рода компенсаторный характер самопрезентации [17].

Второй подход, по мнению его приверженцев, отражает значимость аутентичности личности, стремление к подлинности. Здесь в приоритете морально-нравственные ценности, такие как честь, честность, достоинство, самоуважение и др.

Заключение. Трансформация взглядов на самопрезентацию личности в виртуальном пространстве произошла в последнее десятилетие, что обусловлено динамикой общественных интересов и жизненных смыслов разнопоколенных групп общества. В частности, создание виртуального образа, обладающего реальными чертами индивида-пользователя, актуализирует рефлексивность личности и ее склонность к самоанализу для реализации своих 


\section{ИННОВАЦИОННЫЙ ДИСКУРС РАЗВИТИЯ СОВРЕМЕННОЙ НАУКИ}

сущностных сил и возможностей. Под этим углом зрения, можно сказать, что первый подход, устарел. Такие свойства Интернет- пространства и Интернеткоммуникации как анонимность, гипертекстуальность и пр. были востребованы пользователями в период становления виртуального пространства (конец 1990х - начало 2000-х гг.) [16].

Современный уровень развития межличностных и общественных отношений, инновационных коммуникаций сделал основным трендом самоутверждение личности, потому анонимность и игры с идентичностью в социальных сетях стали не столь актуальны [11].

Таким образом, виртуальное пространство служит средством коммуникации и самопрезентации личности как условия eе самоидентификации в режиме реальных социокультурных практик.

\section{Список литературы}

1. Философский словарь. Фролов И.Т. М., 2001 г. - С. 445 - 447

2. Заковоротная М.В. Идентичность человека. Социально-философские аспекты. Ростов -на-Дону, Издательство Северо-Кавказского научного центра высшей школы. 1999. - 200 с.

3. Спектор Д.М. М. Хайдеггер: время и смысл. // Философская мысль. 2015. - № 10. - С. 1 - 53.

4. Мышкина М.С. Виртуальная самопрезентация как пространство личностной идентичности и мотивационно-смысловой интенции личности. Вестник СамГУ. 2015. №7 (129).

5. Бергер П., Лукман Т. Идентичность ॥ Психология самосознания: хрестоматия \под. ред. Д.Я. Райгородского. Самара: Бахрах М, 2007. С. 567 - 584.

6. Шкуратов И.П. Самопредъявление личности в общении: монография. Ростов н \Дону, Южн. федер. университет, 2009. 192 с.

7. Сураева Г.3. Психологические особенности мотивационно-смысловой интенции личности (социокультурный аспект): автореф.дисс. ...канд.психол. наук. М., 2002. 20 с.)

8. Сураева Г.3. Мышкина М.С. Изучение мотивационно-смысловой сферы личности с использованием метода контент-анализа ответов на незаконченные предложения Дж. Нюттена: учебное пособие. Самара: Изд-во «Универс-групп», 2007 :3 с. 


\section{ИННОВАЦИОННЫЙ ДИСКУРС \\ РАЗВИТИЯ СОВРЕМЕННОЙ НАУКИ}

9. Антонова Н.В. и Одинцова М.С. Интеграционная модель исследования идентичности в контексте интернет-коммуникации // Проблемы практической психоогии.2010. Вып. 2. С. 5 - 16.

10. Гримов О.А. Самопрезентация и самоидентификация личности в социальных сетях // Психология и социология. 2013. Вып. 12.С. 34 - 39.

11. Амяга Н.В. Самораскрытие и самопредъявление личности в общщении // Личность. Общение. Групповые процессы. М., 1991. - С. 37 - 74.

12. Жичкина А.Е., Белинская Е.П. Стратегии самопрезентации в Интернет и их связь с реальной идентичностью. Интернет -ресурс: http:flogiston.rularticleslnetpsylstrategy.

13. Янчук В.А. Введение в современную социальную психологию. Минск: АСАР. - 2005. - 768c.

14. Соколов M.M. Онлайновый дневник, теории виртуальной идентичности и режимы раскрытия персональной информации ЈЛичность и межличностное взаимодействие в сети Интернет. - СПб.:Издательство СПбГУ. -2006 . - C. $9-39$.

15. Белинская Е.П. К проблеме групповой динамики сетевого общества // 2 - ая Российская конференция по экологической психологии. Тезисы. М.: Экопсицентр РОСС. - 2000. - С. 249 - 251.

16. Горный Е.Н. Онтология виртуальной личности.Интернет-ресурс: http:// ecsocman.hse.ru/data/518/878/12`9/05-Hitrov.pdf.

17. Чудова Н.В. Особенности образа Я «жителя» интернета. Интернетpecypc: http://www.psychology.ru /internet/ ecology /07.stm 